\title{
Pupping areas and mortality rates of young tiger sharks Galeocerdo cuvier in the western North Atlantic Ocean
}

\author{
William B. Driggers III*, G. Walter Ingram Jr., Mark A. Grace, \\ Christopher T. Gledhill, Terry A. Henwood, Carrie N. Horton, Christian M. Jones
}

NOAA Fisheries Service, Southeast Fisheries Science Center, Mississippi Laboratories, PO Drawer 1207, Pascagoula, Mississippi 39567, USA

\begin{abstract}
From 1995 through 2006, 2577 bottom longline sets were conducted in the western North Atlantic Ocean from $\sim 36^{\circ} \mathrm{N}, 75^{\circ} \mathrm{W}$ to $26^{\circ} \mathrm{N}, 97^{\circ} \mathrm{W}$, an area that encompasses both the coastal waters off the southeastern USA (Atlantic) and the northern Gulf of Mexico (Gulf). Over the course of the study, 335 young-of-the-year (YOY) and 219 juvenile tiger sharks Galeocerdo cuvier were captured. In the Gulf, YOY catch per unit effort (CPUE) was highest from $\sim 88$ to $83^{\circ} \mathrm{W}$. In the Atlantic, the area of highest YOY CPUE occurred from 31 to $33^{\circ} \mathrm{N}$. Distribution of juvenile tiger sharks was more uniform than observed for YOY throughout the range of the study. Annual survival rates of YOY and Age 1+ tiger sharks were estimated to be 51 and $62 \%$ in the Gulf and 39 and $27 \%$ in the Atlantic. Total instantaneous mortality rates of YOY and Age 1+ tiger sharks were, respectively, estimated to be 0.67 and 0.47 in the Gulf and 0.93 and 1.32 in the Atlantic. In the Atlantic, age-specific natural mortality $(M)$ estimates ranged from 0.12 to 0.50 and from 0.08 to 0.36 for YOY and juvenile tigers sharks, respectively. Estimates of age-specific $M$ were more variable in the Gulf, with values ranging from 0.11 to 0.98 for YOY and from 0.08 to 0.57 for juveniles. In the absence of nursery areas, the production of numerous fast-growing offspring presumably helps the species survive in the face of high total mortality.
\end{abstract}

KEY WORDS: Tiger shark · Galeocerdo cuvier · Carcharhinidae · Pupping area · Nursery area · Mortality

\section{INTRODUCTION}

To manage exploited stocks of marine organisms effectively it may be necessary to identify habitats that are occupied by a species of interest during important periods in its life history. As there is likely to be a strong relationship between adult stock size and recruitment (Smith et al. 1998), elucidating habitats that facilitate the future recruitment of individuals into exploited stocks has become a major research need for fisheries management (NMFS 1999). Habitats that serve a critical role in the sustainability of a given stock include areas used for mating and growth to maturity.

Due to their relatively slow growth, low fecundity and late age at maturity, some shark species are highly susceptible to overfishing (Smith et al. 1998, Cortés 2002). Additionally, many shark species are known to use discrete areas during their life cycle for various purposes, including early growth (Castro 1993); however, the locations of these habitats remain largely unknown for most species. It was first noted by Meek (1916) that some species of sharks use specific areas for parturition. Shark nursery areas can be defined as an area where oviposition or parturition occurs and neonates spend the first months to years of their lives (Springer 1967). When nurseries are located in areas that provide abundant food resources, neonates spend less time at their smallest size, thereby decreasing early mortality rates due to predation (Wourms 1977). Bass (1978) refined the definition of nursery areas and 
characterized nurseries as 'primary' or 'secondary', with primary nurseries being where parturition takes place and neonates remain before moving to secondary nurseries where juveniles occur prior to reaching maturity. The areas inhabited by neonate and juvenile sharks were further divided by Branstetter (1990) into protected or unprotected, with the classification depending on the absence or presence of adult conspecifics.

Recently, in a critical review of the shark nursery area concept, Heupel et al. (2007) suggested that the commonly used definition is ambiguous and can lead to the invalid characterization of a given area as a nursery based solely on the presence of young sharks. Heupel et al. (2007) proposed that a nursery should be defined as a discrete area inhabited by young where (1) their abundance is highest relative to other areas, (2) they show strong site fidelity and (3) it is utilized by successive generations. Based on those criteria, Heupel et al. (2007) determined that fewer areas will be considered nurseries and perhaps will be more appropriately referred to as birthing, pupping, or hatching areas.

In the western North Atlantic Ocean, shallow inshore habitats, such as estuaries, bays, grass flats and lagoons, have been identified as nursery and/or pupping areas for many species of carcharhinid sharks such as blacknose Carcharhinus acronotus, spinner C. brevipinna, finetooth $C$. isodon, bull $C$. leucas, blacktip C. limbatus, sandbar C. plumbeus and Atlantic sharpnose Rhizoprionodon terraenovae sharks (Castro 1993). Conversely, it is unknown if there are discrete nurseries or pupping areas for pelagic carcharhinids such as silky $C$. falciformis and blue Prionace glauca sharks. Anecdotal information suggests that these species give birth in offshore waters (Pratt 1978, Branstetter 1987), which do not provide spatial refuge from larger predators and are generally less productive than inshore waters, thus providing fewer prey resources.

A carcharhinid that cannot be readily characterized as coastal or pelagic is the tiger shark Galeocerdo cuvier. Tiger sharks are distributed circumglobally in temperate and tropical marine waters (Compagno 1984). In the western North Atlantic Ocean, tiger sharks occur in coastal and offshore waters from approximately 40 to $0^{\circ} \mathrm{N}$ and have been documented to make transoceanic migrations (Kohler et al. 1998). Natanson et al. (1998) reported that tiger shark nursery areas in the western North Atlantic Ocean occur at approximately $35^{\circ} \mathrm{N}$ and from $33^{\circ} 45^{\prime}$ to $29^{\circ} 20^{\prime} \mathrm{N}$ along the east coast of the United States, out to a depth of $100 \mathrm{~m}$. Although neonate tiger sharks are frequently caught in the northern Gulf of Mexico, the locations of pupping or nursery areas in this basin have not been identified.
Knowledge pertaining to nursery and/or pupping areas of sharks is essential for accurate and reliable direct estimates of survival. Because of the importance of mortality estimates as a vital rate in population assessments (Cortés 2002), establishing direct estimates of early mortality should be a major objective of shark population dynamics studies. Direct estimates of early mortality are available only for blacktip sharks (Heupel \& Simpfendorfer 2002) and lemon sharks Negaprion brevirostris (Manire \& Gruber 1993, Gruber et al. 2001), and, since knowledge of pupping and nursery areas is limited for many species, natural mortality $(M)$ estimates are often estimated using indirect methods. Age-independent indirect methods result in $M$ estimates that are constant across all age classes, while age-dependent indirect methods provide $M$ estimates for each age class (Peterson \& Wroblewski 1984, Chen \& Watanabe 1989). As $M$ has been shown to be highest for young sharks (Manire \& Gruber 1993, Heupel \& Simpfendorfer 2002), age-independent $M$ estimates for juvenile sharks are lower than would be found using direct methods (Heupel \& Simpfendorfer 2002).

The objective of this study was to analyze data collected during fishery independent surveys conducted throughout the coastal waters off the southeastern United States and the northern Gulf of Mexico to (1) investigate spatial trends in abundance of neonate and juvenile tiger sharks, (2) examine potential use of discrete areas as tiger shark nurseries or pupping areas, and (3) provide total mortality $(Z)$ estimates, which are the combined result of natural and fishing related mortality, for young-of-the-year (YOY) and Age 1+ tiger sharks in the western North Atlantic Ocean.

\section{MATERIALS AND METHODS}

From 1995 through 2006, the NOAA Fisheries Service, Southeast Fisheries Science Center, Mississippi Laboratories, conducted bottom longline surveys in the western North Atlantic Ocean. The study area extended from $\sim 36^{\circ} 00^{\prime} \mathrm{N}, 75^{\circ} 00^{\prime} \mathrm{W}$ to $26^{\circ} 00^{\prime} \mathrm{N}, 97^{\circ} 00^{\prime} \mathrm{W}$ : an area that encompasses waters off the coast of the southeastern USA (Atlantic) and the northern Gulf of Mexico (Gulf) (Fig. 1). Surveys were generally conducted annually in the Gulf and biennially in the Atlantic from August to September. The entire study area was not sampled in all years due to logistical constraints or adverse weather. Bottom longline gear was set at depths ranging from 9 to $183 \mathrm{~m}$ in the Atlantic and 9 to $366 \mathrm{~m}$ in the Gulf. Locations were randomly selected by stratified-random sampling with proportional allocation. Strata were defined by water depth with stratum size determined by continental shelf area. 


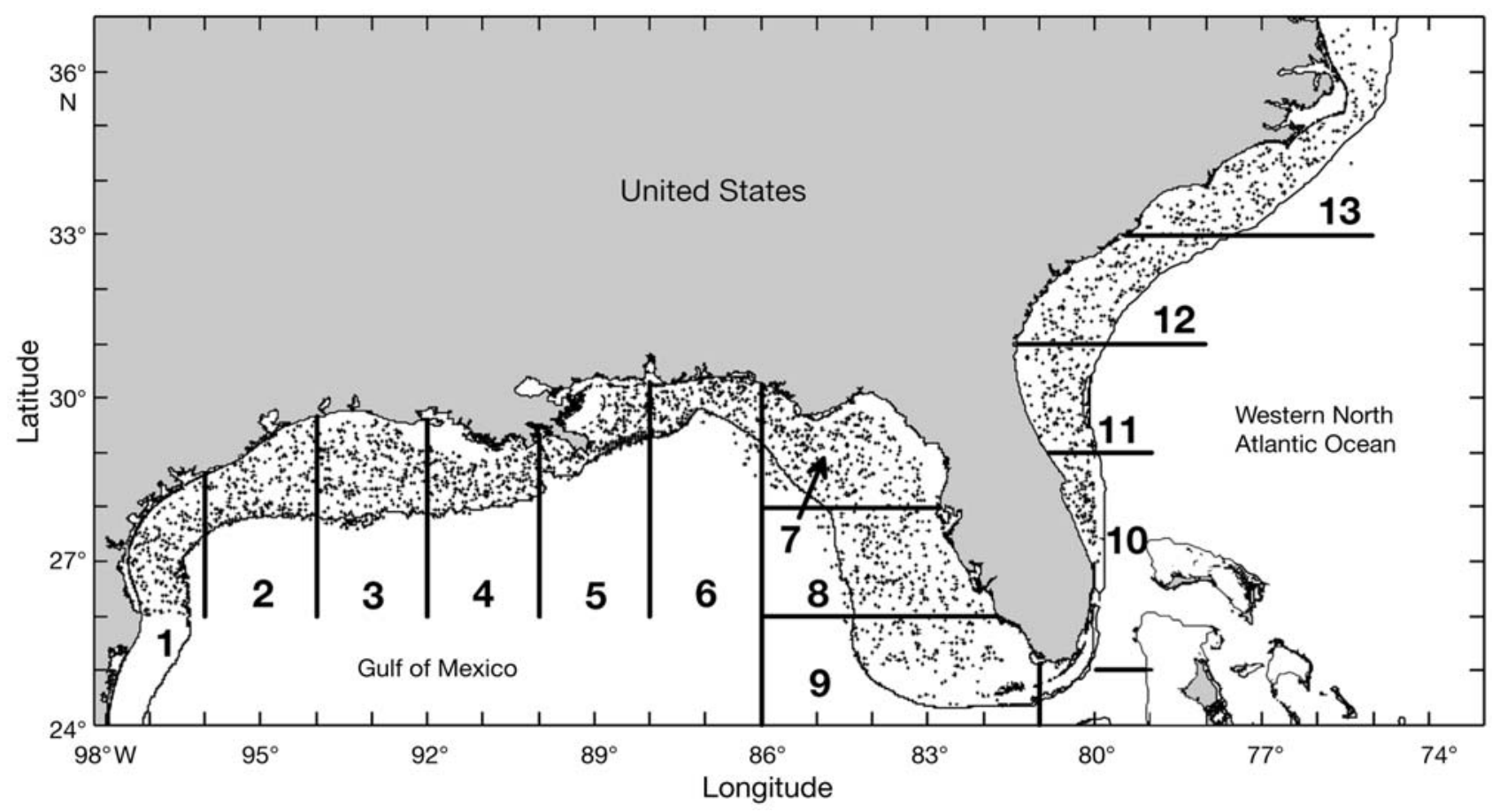

Fig. 1. Galeocerdo cuvier. Zones used to analyze the spatial distribution of tiger sharks caught during NOAA Fisheries Service bottom longline surveys. Each point represents the location of a sampling station where longline gear was deployed from 1995 to 2006 . The $200 \mathrm{~m}$ isobath is shown

Longline gear consisted of $1852 \mathrm{~m}$ of $536 \mathrm{~kg}$ test monofilament mainline and 100 gangions, which were constructed of a snap, $3.7 \mathrm{~m}$ of $332 \mathrm{~kg}$ test monofilament leader and a hook. Hook type varied, with No. 3 J-hooks (Mustad, Model No. 34970D) used from 1995 through 1998 and 15/0 circle hooks (Mustad, Model No. 39960D) used from 2001 to 2006; during 1999 and 2000 both hook types were used. Soak times were limited to $1 \mathrm{~h}$ unless circumstances dictated otherwise. The sex of each tiger shark captured was recorded, and fork length (FL) and weight were measured to the nearest millimeter and $0.1 \mathrm{~kg}$, respectively. Fork length was measured on a straight line along the axis of the body, from the tip of the snout to the posterior notch of the caudal fin.

Catch per unit effort (CPUE, number per 100 hookhours) was calculated using the following formula:

$$
\text { CPUE }=\left(\frac{C}{h \times t}\right) \times 60 \times 100
$$

where $c$ equals the number of tiger sharks captured, $h$ equals the number of hooks deployed and $t$ equals soak time in minutes. The multipliers of $60 \mathrm{~min}$ and 100 hooks were used to standardize CPUE data as number of sharks captured per 100 hook-hours. Number of hooks deployed was held constant at $100 \mathrm{set}^{-1}$, and the number of hooks missing upon retrieval was used in the analyses which led to conservative estimates of CPUE. This was done because we had no way of knowing whether the hook was removed from the gangion due to entanglement with the bottom or resulted from an interaction with a captured organism. To examine the distribution of YOY and juvenile tiger sharks throughout the study area, CPUE pooled from all years was calculated for both life stages. The age of each tiger shark captured was determined by backtransforming age from length at capture, using the most current von Bertalanffy growth function (VBGF) parameter estimates $\left(L_{\infty}=\right.$ theoretical asymptotic length, $k=$ growth coefficient, $t_{0}=$ theoretical age at zero length) from the Gulf (Branstetter et al. 1987; $L_{\infty}=$ $388 \mathrm{~cm}, k=0.184, t_{0}=-1.13 \mathrm{yr}$ ) and the Atlantic (Kneebone et al. $\left.2008 ; L_{\infty}=361 \mathrm{~cm}, k=0.102, t_{0}=-2.24 \mathrm{yr}\right)$. With the exception of YOY tiger sharks, all individuals $<1800 \mathrm{~mm}$ FL were considered juveniles. We assumed that catchability did not differ between the 2 life stages considered.

The study area was separated into 13 zones for analytical purposes (Fig. 1). A power analysis was run to determine the minimum number of stations needed in each zone to discern differences among zones. This was accomplished by taking the overall mean CPUE and standard error (SE) for the entire study, assuming these approximated to the population mean CPUE and $\mathrm{SE}$, and varying the sample size $(\mathrm{N})$ until a coefficient of variation (i.e. $\mathrm{CV}=\mathrm{SE} /$ mean $\mathrm{CPUE}$ ) of 0.5 was found. With a CV of approximately 0.5, differences between means can usually be discerned at a signifi- 
cance level (i.e. $\alpha$ ) of 0.05 . The power analysis indicated a minimum of approximately 115 stations were needed in each zone to discern differences between them, and with the configuration shown in Fig. 1, all zones except Zone 10 met this criterion. This result also precluded analyses between zones for each year, due to low sample sizes of stations within individual years.

To examine the distribution of tiger sharks by life stage, CPUE values among zones were compared for each age class using a linear mixed model. This was accomplished using a backward step-wise selection methodology based on Type 3 analyses (significance level for variable retention set at $\alpha=0.05$ ) with the MIXED procedure in SAS. The model, which included CPUE as the dependent variable, included geographic zone, station depth, and hook type as descriptor variables, and a year-specific covariance structure that incorporated an exponential, 2-dimensional (with latitude and longitude), spatial covariance structure to account for any spatial autocorrelation. Least-squares mean CPUE values were estimated for each zone, and multiple comparison procedures were performed between zone CPUE values independently for each age class.

After backtransforming age at size, annual survival $(S)$ and total instantaneous mortality $(Z)$ were estimated for YOY and Age 1+ tiger sharks using the following equations:

$$
S_{0}=\frac{N_{0}-N_{1}}{N_{0}} \text { and } Z_{0}=-\ln \left(S_{0}\right)
$$

for YOY tiger sharks, and

$$
S_{1}=\frac{N_{1}-N_{2}}{N_{1}} \text { and } Z_{1}=-\ln \left(S_{1}\right)
$$

for Age 1+ tiger sharks, where $N_{0}, N_{1}$ and $N_{2}$ equal the number of tiger sharks collected at 0,1 and 2 yr of age; $S_{0}$ and $S_{1}$ equal the annual survival of YOY and Age 1+ tiger sharks; and $Z_{0}$ and $Z_{1}$ equal the total instantaneous mortality of YOY and $1 \mathrm{yr}$ old tiger sharks. These analyses assumed that YOY, Age 1+ and Age 2+ tiger sharks were fully recruited to the gear, $Z$ was constant for each age class, there was no interannual variability in mortality, recruitment was constant among years, there was no size-related gear selectivity for YOY, Age 1+ and Age $2+$ size classes and longline sampling included the geographic range of all 3 age classes (i.e. no emigration).

Four indirect age-dependent methods of estimating $M$ of YOY and Age 1+ tiger sharks were utilized and compared to $Z$ estimates derived from catch curve analyses. (1) The Peterson and Wrob- lewski method (PWM), $M_{W}=1.92 w_{t}^{-0.25}$, is based on weight-at-age data where $w$ is the mean weight of tiger sharks within each age class, $t$ (Peterson \& Wroblewski 1984). Estimates of $M$ were calculated based on both mean wet $\left(\mathrm{PWM}_{\mathrm{ww}}\right)$ and dry weights $\left(\mathrm{PWM}_{\mathrm{dw}}\right)$. (2) The Lorenzen method for estimating natural mortality in ocean ecosystems (LM), $M_{W}=$ $3.69 W^{-3.05}$, where $W$ is mean weight-at-age, is also based on weight-at-age data (Lorenzen 1996). Mean wet weight for YOY and Age 1+ tiger sharks was calculated using observed length and weight data collected from the juvenile tiger sharks caught during this study. Mean dry weight was calculated by multiplying the mean wet weight by 0.20 (Cortés 2002). (3) The Chen and Watanabe method (CWM), which calculates mortality for the immature phases of a species' life cycle, utilizes VBGF parameter estimates to estimate natural mortality (Chen \& Watanabe 1989) such that:

$$
M(t)=\frac{k}{1-\mathrm{e}^{-k\left(t-t_{0}\right)}}
$$

where $k$ is the theoretical growth constant, and $t$ is age. (4) Region-specific VBGF parameter estimates for combined sexes are those of Kneebone et al. (2008) for the Atlantic and Branstetter et al. (1987) for the Gulf. To estimate fishing mortality $(F)$, region and age-specific estimates of $Z$ and $M$ were utilized in the following equation: $F=Z-M$. The commercial catch of tiger sharks in the Atlantic and Gulf during the study period was analyzed by accessing the NMFS annual commercial catch landings database (NMFS 2007). Because the standard deviations of mean catch were significantly different between the 2 areas, a Kolmogorov-Smirnoff (K-S) test was used to compare distributions.

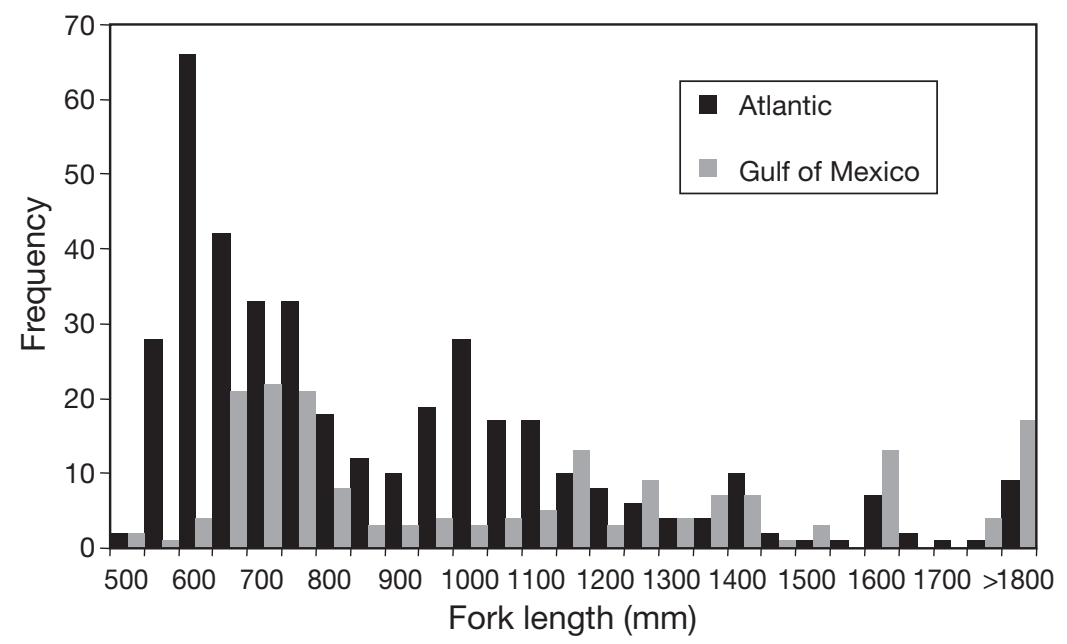

Fig. 2. Galeocerdo cuvier. Length frequency of tiger sharks caught off the coast of the SE USA and in the northern Gulf of Mexico from 1995 to 2006 


\section{RESULTS}

Over the course of the study 2577 longline sets were completed, resulting in the capture of 335 YOY and 219 juvenile tiger sharks. Two distinct modes, at 600 and $1000 \mathrm{~mm}$ FL in the Atlantic and 700 and $1100 \mathrm{~mm}$ FL in the Gulf indicated that YOY and Age 1+ tiger sharks in the Atlantic were smaller than conspecifics in the Gulf (Fig. 2). Mean $( \pm$ SD) length was $796.71 \pm$ $188.51 \mathrm{~mm}$ FL in the Atlantic and $850.54 \pm 220.97 \mathrm{~mm}$ FL in the Gulf. Regression analyses indicated that the relationship between length and weight for juvenile tiger sharks was best described by the equation: weight $(\mathrm{kg})=[-1.37313+0.0044249 \times \mathrm{FL}(\mathrm{mm})]^{2}$.

Both YOY and juvenile abundances were significantly different among geographic zones and station depths (Type 3 tests for zone: YOY, $p<0.01$; juvenile, $\mathrm{p}<0.01$, and Type 3 tests for station depth: YOY, $\mathrm{p}=$ 0.02 ; juvenile, $\mathrm{p}=0.01$ ); however, hook type was not significant (Type 3 tests for hook type: YOY, $\mathrm{p}=0.26$; juvenile, $p=0.66$ ). Moreover, the multiple comparison procedures performed on least-squares mean CPUE indicated differences among zones for YOY and juveniles (Table 1). There was no statistical difference among zones in CPUE for YOY tiger sharks in the Gulf of Mexico; however, Zones 6 and 7 had the highest observed CPUE values (Fig. 3, Table 1). Zone 12,
Table 1. Galeocerdo cuvier. Mean catch per unit effort (CPUE; mean $\pm \mathrm{SE}$ ) (number caught per 100 hook hours) of young-ofthe-year and juvenile tiger sharks by zone (geographic zones shown in Fig. 1) caught in the South Atlantic Bight and northern Gulf of Mexico during bottom longline surveys from 1995 to 2006. N: number of longline sets conducted in each corresponding zone. Sig.: differences in letters among zones indicate significant differences in CPUE values exist. Those with overlapping letters are not statistically different $(\alpha=0.05)$

\begin{tabular}{|c|c|c|c|c|c|c|c|}
\hline \multicolumn{4}{|c|}{-Young-of-the-year } & \multicolumn{4}{|c|}{ - Juvenile } \\
\hline Zone & $\mathrm{N}$ & CPUE & Sig. & Zone & $\mathrm{N}$ & CPUE & Sig. \\
\hline 12 & 157 & $1.08 \pm 0.11$ & A & 11 & 115 & $0.32 \pm 0.04$ & A \\
\hline 11 & 115 & $0.47 \pm 0.12$ & B & 13 & 195 & $0.26 \pm 0.04$ & A \\
\hline 13 & 195 & $0.26 \pm 0.10$ & $\mathrm{BC}$ & 12 & 157 & $0.25 \pm 0.04$ & A \\
\hline 6 & 228 & $0.12 \pm 0.09$ & C & 6 & 228 & $0.10 \pm 0.03$ & B \\
\hline 7 & 287 & $0.10 \pm 0.08$ & $\mathrm{C}$ & 7 & 287 & $0.08 \pm 0.03$ & B \\
\hline 10 & 104 & $0.07 \pm 0.13$ & $\mathrm{C}$ & 5 & 263 & $0.06 \pm 0.03$ & B \\
\hline 9 & 137 & $0.04 \pm 0.11$ & $\mathrm{C}$ & 10 & 104 & $0.05 \pm 0.04$ & B \\
\hline 5 & 263 & $0.03 \pm 0.09$ & $\mathrm{C}$ & 9 & 137 & $0.05 \pm 0.04$ & B \\
\hline 8 & 220 & $0.03 \pm 0.09$ & $\mathrm{C}$ & 2 & 220 & $0.04 \pm 0.03$ & B \\
\hline 2 & 220 & $0.02 \pm 0.09$ & $\mathrm{C}$ & 3 & 267 & $0.04 \pm 0.03$ & B \\
\hline 3 & 267 & $0.00 \pm 0.09$ & $\mathrm{C}$ & 1 & 180 & $0.04 \pm 0.04$ & B \\
\hline 4 & 204 & $0.00 \pm 0.10$ & $\mathrm{C}$ & 4 & 204 & $0.02 \pm 0.03$ & B \\
\hline 1 & 180 & $0.00 \pm 0.10$ & $\mathrm{C}$ & 8 & 220 & $0.02 \pm 0.03$ & B \\
\hline
\end{tabular}

which extends from 31 to $33^{\circ} \mathrm{N}$, had a significantly higher CPUE for YOY tiger sharks than any other zone in the Atlantic (Table 1). Zone 10 had the lowest CPUE for YOY sharks in the Atlantic and corresponded to the

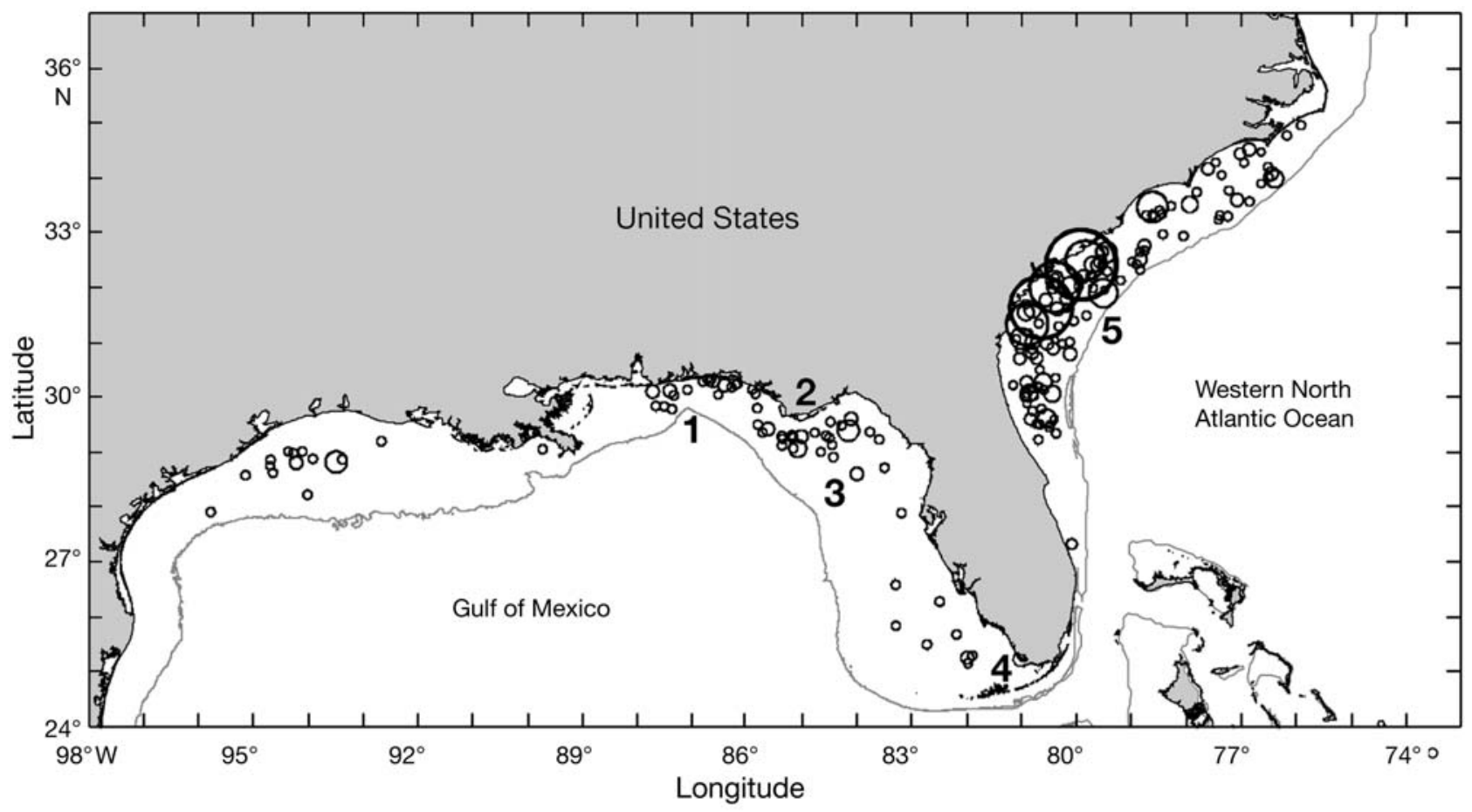

Fig. 3. Galeocerdo cuvier. Distribution of young-of-the-year tiger sharks from 1995 to 2006. Circle diameter is linearly related to catch per unit effort (number caught per 100 hook hours; smallest circle $=1$, largest circle $=15$ ). Locations referred to in text are indicated-1: Desoto Canyon; 2: Cape San Blas; 3: West Florida Shelf; 4: Florida Keys; 5: Charleston Bump. The $200 \mathrm{~m}$ isobath is shown 
southern portion of the tiger shark nursery proposed by Natanson et al. (1998). Distribution of juvenile tiger sharks was more uniform than observed for YOY throughout the range of the study (Fig. 4, Table 1). In the Gulf, CPUE of juveniles did not differ among zones, while in the Atlantic those values were highest in Zones 11, 12 and 13.

Annual survival rates of YOY and Age 1+ tiger sharks were estimated to be 51 and $62 \%$ in the Gulf and 39 and $27 \%$ in the Atlantic. Total instantaneous mortality rates of YOY and Age 1+ tiger sharks were estimated to be 0.67 and 0.47 in the Gulf and 0.93 and 1.32 in the Atlantic. In the Atlantic, age-specific $M$ estimates ranged from 0.12 to 0.50 and 0.08 to 0.36 for YOY and juvenile tigers sharks, respectively (Table 2). Estimates of age-specific $M$ were more variable in the Gulf, with values ranging from 0.11 to 0.98 for YOY and 0.08 to 0.57 for juveniles. In all cases, $M$ estimates were lowest using the $\mathrm{PWM}_{\mathrm{ww}}$ and highest with the CWM.

Within the commercial fishery operating in United States Atlantic and Gulf waters, tiger shark landings were significantly higher in the Atlantic than in the Gulf (K-S statistic $=1.96, \mathrm{p}<0.01)$. Between 1995 and 2005, yearly tiger shark landings in the Atlantic ranged from 1.0 to $20.7 \mathrm{mt}$ (mean $=7.41, \mathrm{SD}=5.09$ ) and from 0.2 to $1.8 \mathrm{mt}$ in the Gulf (mean $=0.78, \mathrm{SD}=$ $0.53)$.
Table 2. Galeocerdo cuvier. Mortality estimates for young-ofthe-year (YOY) and Age 1+ tiger sharks off the Atlantic coast of the USA and in the northern Gulf of Mexico. Instantaneous rates of total mortality $(Z)$ and survivorship $(S)$ estimates are from the current study. Estimates of instantaneous rates of natural mortality $(M)$ were calculated using equations presented by Peterson \& Wroblewski (1984), with ${ }^{1}$ wet weight and ${ }^{2}$ dry weight (see 'Materials and methods' for details), ${ }^{3}$ Chen \& Watanabe (1989) and ${ }^{4}$ Lorenzen (1996). Fishing mortality $(F)$ estimates were derived by calculating the difference between $Z$, from the present study, and $M$ estimated by the 4 age-dependent $M$ estimates

\begin{tabular}{|lcccr|}
\hline Age & $S$ & $Z$ & $M$ & $F$ \\
\hline Atlantic & & & & \\
YOY & 0.39 & 0.93 & $0.12^{1}$ & $0.81^{1}$ \\
& & & $0.17^{2}$ & $0.76^{2}$ \\
& & & $0.50^{3}$ & $0.43^{3}$ \\
Age 1+ & 0.27 & \multirow{2}{*}{1.32} & $0.32^{4}$ & $0.61^{4}$ \\
& & & $0.12^{2}$ & $1.24^{1}$ \\
& & & $0.36^{3}$ & $0.96^{2}$ \\
Northern Gulf & & & $0.22^{4}$ & $1.10^{4}$ \\
YOY & 0.51 & 0.67 & $0.11^{1}$ & $0.56^{1}$ \\
& & & $0.16^{2}$ & $0.51^{2}$ \\
& & & $0.98^{3}$ & $-0.31^{3}$ \\
Age 1+ & & & $0.30^{4}$ & $0.37^{4}$ \\
& 0.63 & 0.47 & $0.08^{1}$ & $0.39^{1}$ \\
& & & $0.11^{2}$ & $0.36^{2}$ \\
& & & $0.57^{3}$ & $-0.10^{3}$ \\
& & & $0.20^{4}$ & $0.27^{4}$ \\
\hline
\end{tabular}

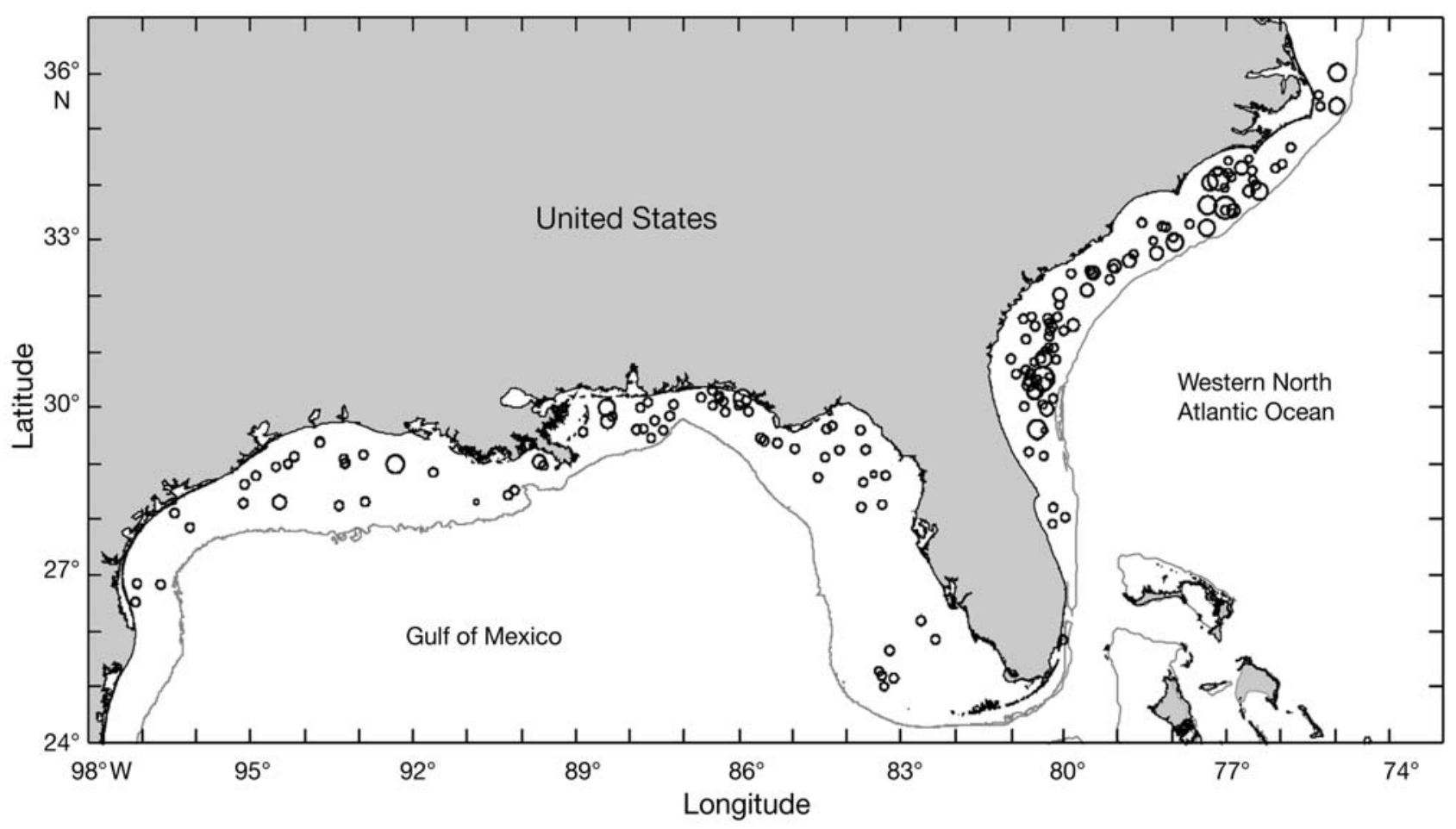

Fig. 4. Galeocerdo cuvier. Distribution of juvenile tiger sharks from 1995 to 2006. Circle diameter is linearly related to catch per unit effort (number caught per 100 hook hours; smallest circle $=1$, largest circle $=4$ ). The $200 \mathrm{~m}$ isobath is shown 


\section{DISCUSSION}

Tiger sharks in the western North Atlantic Ocean do not use specific areas as nurseries, as defined by Heupel et al. (2007). It does appear, however, that parturition occurs over a broad range, with areas of high neonate abundance that could be considered important pupping areas. The general pupping area for neonate tiger sharks in the Atlantic extends from at least 27 to $35^{\circ} \mathrm{N}$, an area larger than previously reported for that region by Natanson et al. (1998). While neonates occur throughout this range, the region from 31 to $33^{\circ} \mathrm{N}$ probably represents the most important pupping area for tiger sharks as indicated by CPUE data; however, as our sampling did not occur in the northernmost portion of the range of tiger sharks in the Atlantic, we cannot discount the presence of an important pupping area in that region. Prior to this study, it was unknown whether a tiger shark pupping area occurred in the Gulf. Neonate tiger sharks occur throughout the basin in waters $<100 \mathrm{~m}$, and, based on CPUE data, the 2 areas of highest abundance were between 83 and $88^{\circ} \mathrm{W}$ and 93 and $95^{\circ} \mathrm{W}$.

The locations of highest YOY abundance in the western North Atlantic Ocean are likely to be influenced by areas of high localized productivity. In the Atlantic, the area of highest YOY abundance corresponds to an area of increased productivity, resulting from upwelling associated with the western boundary of the Gulf Stream and the Charleston Bump, which is thought to produce the Charleston Gyre. This gyre contains nutrient-rich water that likely supports increased prey resources (Govoni \& Hare 2001). Similarly, in the eastern Gulf, a bloom of phytoplankton occurs on the West Florida Shelf during winter and spring, resulting from riverine discharge, circulatory patterns of the Loop Current and upwelling of nutrient-rich water from the DeSoto Canyon (Gilbes et al. 1996, Castillo et al. 2000). While this bloom can extend southward to the Florida Keys, it originates off Cape San Blas (Zone 7) (Castillo et al. 2000), where the highest CPUE of YOY tiger sharks occurred in the Gulf (specific locations indicated in Fig. 3).

Although neonates were distributed throughout the Atlantic and the Gulf, it is possible the primary pupping areas are discrete locations where parturition occurs from where neonates disperse. Sampling in both areas took place approximately 2 mo after the assumed tiger shark parturition period (based on monthly length-frequency data presented by Natanson et al. [1998] for early summer). Since the highest concentration of YOY in the Atlantic occurred at approximately $32^{\circ} \mathrm{N}$, the observed distribution of YOY and juveniles would require neonates to disperse up to $550 \mathrm{~km}$ in the 2 mo time interval between parturition and our sampling. Similarly, in the Gulf, if the main pupping areas for tiger sharks are centered on 85 and $94^{\circ} \mathrm{W}$, the longitudinal distribution of neonates outside of these areas is no greater than $440 \mathrm{~km}$. There is limited data for neonate tiger shark swimming speeds to support these hypothesized movements; however, evidence suggests these sharks are capable of traveling distances $>550 \mathrm{~km}$ in a 2 mo period. Off the coast of Hawaii, the average swimming speed of juvenile and adult tiger sharks was experimentally determined to be $3.85 \mathrm{~km} \mathrm{~h}^{-1}$ (Holland et al. 1999). Based on the reported swimming speed, and assuming continuous swimming in a straight line and negating energetic demands, it is theoretically possible that juvenile and adult tiger sharks are capable of covering a distance in excess of $5500 \mathrm{~km}$ over a 2 mo period; an order of magnitude greater than would be necessary to explain the distribution of neonate tiger sharks we observed.

Juvenile tiger sharks were relatively evenly distributed throughout the study area and were more abundant in the Atlantic than in the Gulf. The areas of highest abundance were in Zones 11 and 13, which are both adjacent to the proposed main pupping area in Zone 12. The distribution of juveniles in the Gulf was relatively uniform. The uniform distribution of juvenile tiger sharks in both regions supports the use of discrete pupping areas within the Atlantic. If parturition of YOY tiger sharks occurs throughout their range in the Atlantic and Gulf, rather than in discrete areas, it is possible they migrate to the areas mentioned above for the purposes of feeding. However, if areas of increased productivity attract YOY, then juveniles would likely be attracted to the same areas. Therefore, as there are no areas of increased juvenile abundance associated with areas of high productivity, it is probable that parturition occurs in the areas where neonates remain until their first large-scale migration.

Instantaneous rates of mortality of YOY and Age 1+ tiger sharks were higher in the Atlantic than in the Gulf. Region-specific differences in the landings by the commercial fishery could largely account for this. Total landings of tiger sharks are higher in the Atlantic than in the Gulf. Furthermore, of the tiger sharks discarded in the commercial fishery, fewer individuals are released alive in the Atlantic than in the Gulf (Hale \& Carlson 2007). A more significant finding is that in the Atlantic, Age 1+ mortality was greater than YOY mortality. The higher mortality rate of Age 1+ tiger sharks could be attributed to higher natural mortality, greater fishing mortality, or emigration that was unaccounted for of Age 1+ sharks out of the survey area. It is probable that predation rates, and thus natural mortality, would decrease as juveniles increase in age and size because of gape limitations of potential predators and the increase in swimming efficiency associated with size (Wourms 1977). If these hypotheses are applicable 
to tiger sharks, then high natural mortality of Age 1+ tiger sharks must be in part attributed to the latter 2 causes. The mean size of tiger sharks caught in the directed shark longline fishery operating in the Atlantic and Gulf is 1119 and 1063 mm FL, respectively (Smith et al. 2006). These sizes correspond to an age of $1.40 \mathrm{yr}$ in the Atlantic and $1.22 \mathrm{yr}$ in the Gulf (age backtransformed as described earlier). While the size and age of tiger sharks captured in both basins are similar, the lower $Z$ of YOY and Age 1+ tiger sharks in the Gulf could be related to fishing pressure. The commercial fishery operating in the western North Atlantic Ocean frequently captures juvenile tiger sharks; however, until they attain a size of at least $9 \mathrm{~kg}$, they are typically not retained as their meat, skin and fins have little value (R. Hudson, Directed Shark Fisheries, Inc., pers. comm.). Using our length-weight regression for juvenile tiger sharks and backtransforming the resulting value (previously described), the age of a $9 \mathrm{~kg}$ tiger shark would be $0.90 \mathrm{yr}$ in the Atlantic and $1.02 \mathrm{yr}$ in the Gulf. Although the mean size and age of tiger sharks landed in both regions are similar, that tiger sharks landings are significantly higher in the Atlantic than in the Gulf could explain the disparity in Z. Emigration of Age 1+ tiger sharks from our survey area could have significantly biased our results and led to inflated estimates of $Z$ in the Atlantic. We are not aware of any age-specific tiger shark tag-recapture data from the western North Atlantic Ocean, and, therefore, cannot quantitatively assess the effects of emigration on our estimates; however, we would expect to observe a similar $Z$ in the Gulf if emigration heavily biased our results. Therefore, because of the significantly higher commercial landings of tiger sharks in the Atlantic, we attribute the higher mortality of Age 1+ tiger sharks in the Atlantic to $F$. Future research investigating agespecific movement patterns of tiger sharks in the western North Atlantic Ocean will be needed to examine the impacts of emigration on our $Z$ estimates.

Despite the importance of age-specific mortality rates for the purposes of demographic analyses (Cortés 1998), few direct mortality estimates exist, thus requiring analysts to estimate this parameter. As a result, it is common for a range of indirect mortality estimates to be employed, which can lead to high variability in estimates of rebound potential and recovery period. Direct $Z$ estimates exist for neonates of 2 carcharhinid species and range from 0.43 to 1.01 for lemon sharks (Manire \& Gruber 1993, Gruber et al. 2001) and 0.61 to 0.91 for blacktip sharks (Heupel \& Simpfendorfer 2002) (lower range of lemon shark $Z$ estimate derived from $S$ reported by Gruber et al. [2001] using the algorithm $Z=$ $-\ln [S])$. The direct $Z$ estimates for YOY tiger sharks in the present study were within the range of $Z$ estimates reported for neonate lemon and blacktip sharks, with the exception of YOY tiger sharks in the Atlantic, where $Z$ exceeded that for blacktip sharks.

Instantaneous natural mortality rates differed among the 4 methods used for its calculation. Regardless of age class or area, the $\mathrm{PWM}_{\mathrm{ww}}$ and CWM consistently resulted in the lowest and highest $M$ estimates, respectively. The CWM is based on VBGF parameter estimates and is therefore limited by the accuracy of the growth models used as inputs. How accurately the VBGF parameters of Branstetter et al. (1987) and Kneebone et al. (2008) describe the growth of tiger sharks in the Atlantic and Gulf is unknown; however, they are the most updated growth models for the species within our survey area. The PWM, regardless if being based on wet or dry weight, resulted in lower $M$ estimates. It has been suggested that the PWM accurately defines $M$ over a broad size range of aquatic animals (McGurk 1986). However, since tiger shark neonates are not isolated from larger predators during their most vulnerable phase of life and the $M$ estimates of the CWM and LM were approximately twice that of the PWM, our $M$ estimate based on the PWM may be too low. The LM resulted in $M$ estimates intermediate to the values predicted by the other 3 methods and that are an approximate mean value of those values resulting from the CWM and PWM. Since the estimate of $M$ from each method varies, we recommend stock assessment analysts should use either just LM estimates of $M$ for their analyses, or all 4 to conduct a sensitivity analysis over a range of values.

Although the estimates of $Z, F$ and $M$ determined in this study are uncertain, $M$ probably contributes significantly to $Z$ for YOY and Age $1+$ tiger sharks. With the exception of blue sharks, tiger shark neonates are smaller relative to maternal size than all other carcharhinids (Cortés 2000). Small size at birth is associated with high natural mortality due to low predatory efficiency and high predation (Wourms 1977). Low predatory efficiency of tiger sharks could result from their inefficient swimming motion resulting from their bodies being extremely flexible, and the lower thrust angle of the upper lobe of their caudal fin relative to that of older conspecifics (Branstetter et al. 1987). High natural mortality could also be a result of pupping areas occurring in areas of high predator abundance.

All species within the family Carcharhinidae, with the exception of tiger sharks, are placentally viviparous, including those that have offshore pupping areas. Placental viviparity is generally typified by low reproductive output with neonates being large relative to maternal size (Wourms 1977). This reproductive strategy maximizes neonate survival through size-related reduction in the number of potential predators and increased predatory efficiency, thus minimizing $M$. Tiger sharks, however, are aplacentally viviparous; a 
reproductive mode associated with relatively high fecundity and the production of neonates that are small compared to maternal size. It has been hypothesized that the aplacentally viviparous reproductive mode utilized by tiger sharks is secondarily derived rather than a retention of the ancestral condition. Phylogenetic and molecular analyses of reproductive modes observed among elasmobranchs support this hypothesis (Dulvy \& Reynolds 1997, López et al. 2006). Furthermore, Compagno (1984) indicated that this condition was likely secondarily derived as placental viviparity is observed in the family Hemigalidae, which is a sister group of the family Carcharhinidae. Therefore, if aplacental viviparity is secondarily derived in tiger sharks, reverting to the ancestral condition could represent a compensatory mechanism to increase cohort strength due to high $M$.

Because of the relatively low fecundity and late onset of maturation typical of many shark species, management strategies needed to ensure their proliferation must be carefully considered given the high rate of targeted and incidental exploitation of these fishes. Information pertaining to the life-history and population dynamics of most species remains limited (Cortés 2000) and as a result makes their management difficult. Direct estimates of species-specific mortality rates and locations of critical habitats are examples of information needed to facilitate accurate stock assessments and coordinate management measures. To our knowledge, our study is the first to provide direct mortality estimates for tiger sharks and defines pupping areas that should be considered critical habitat for this species in the western North Atlantic Ocean.

Acknowledgements. We thank L. Jones, D. Landi, K. Mitchell, the crews of the NOAA research vessels 'Caretta', 'Ferrell', 'Gandy', 'Gunter', and 'Oregon II' and all those who participated on NMFS/MSLABS bottom longline surveys. We thank R. Hudson providing information on the commercial shark fishery. Finally, we acknowledge J. Carlson, E. Cortés and the 3 anonymous reviewers for their useful comments.

\section{LITERATURE CITED}

Bass AJ (1978) Problems in studies of sharks in the southwest Indian Ocean. In: Hodgson ES, Mathewson RF (eds) Sensory biology of sharks, skates and rays. Office of Naval Research, Department of the Navy, Arlington, VA, p 545-594

Branstetter S (1987) Age, growth and reproductive biology of the silky, Carcharhinus falciformis, and the scalloped hammerhead, Sphyrna lewini, from the northwestern Gulf of Mexico. Environ Biol Fishes 19:161-173

Branstetter S (1990) Early life-history implications of selected carcharhinoid and lamnoid sharks of the northwest Atlantic. In: Pratt HL Jr, Gruber SH, Taniuchi T (eds) Elasmobranchs as living resource: advance in biology, ecology, systematics and the status of fisheries. NOAA
Tech Rep 90:17-28

Branstetter S, Musick JA, Colvocoresses JA (1987) A comparison of the age and growth of the tiger shark, Galeocerdo cuvier, from off Virginia and from the northern Gulf of Mexico. Fish Bull (Wash DC) 85:269-279

Castillo CED, Gilbes F, Coble PG, Müller-Karger FE (2000) On the dispersal of riverine colored dissolved organic matter over the West Florida Shelf. Limnol Oceanogr 45: $1425-1432$

Castro JI (1993) The shark nursery of Bulls Bay, south Carolina, with a review of the shark nurseries of the southeastern coast of the United States. Environ Biol Fishes 38:37-48

Chen S, Watanabe S (1989) Age dependence of natural mortality coefficient in fish population dynamics. Nippon Suisan Gakkaishi 55:205-208

Compagno LJV (1984) FAO species catalog, Vol 4. Sharks of the world: an annotated and illustrated catalogue of shark species known to date. Part 2: Carcharhiniformes. FAO Fish Synop (125) Vol 4, Pt. 2:251-655

Cortés E (1998) Demographic analysis as an aid in shark stock assessment and management. Fish Res 39:199-208

Cortés E (2000) Life-history patterns and correlations in sharks. Rev Fish Sci 8:299-344

> Cortés E (2002) Incorporating uncertainty into demographic modeling: application to shark populations and their conservation. Conserv Biol 16:1048-1062

Dulvy NK, Reynolds JD (1997) Evolutionary transitions among egg-laying, live-bearing and maternal inputs in sharks and rays. Proc R Soc Lond 264:1309-1315

Gilbes F, Thomas C, Walsh JJ, Müller-Karger FE (1996) An episodic chlorophyll plume on the West Florida Shelf. Cont Shelf Res 16:1201-1207

Govoni JJ, Hare JA (2001) The Charleston Gyre as a spawning and larval nursery habitat for fishes. In: Sedberry G (ed) Island in the stream: oceanography and fisheries of the Charleston Bump. Am Fish Soc Symp 25:123-136

> Gruber SH, De Marignac JRC, Hoenig JM (2001) Survival of juvenile lemon sharks at Bimini, Bahamas, estimated by mark-depletion experiments. Trans Am Fish Soc 130: $376-384$

Hale LF, Carlson JK (2007) Characterization of the shark bottom longline fishery: 2005-2006. NOAA Tech Mem no. 554

> Heupel MR, Simpfendorfer CA (2002) Estimation of mortality of juvenile blacktip sharks, Carcharhinus limbatus, within a nursery area using telemetry data. Can J Fish Aquat Sci 59:624-632

> Heupel MR, Carlson JK, Simpfendorfer CA (2007) Shark nursery areas: concepts, definition, characterization and assumptions. Mar Ecol Prog Ser 337:287-297

> Holland KN, Wetherbee BM, Lowe CG, Meyer CG (1999) Movements of tiger sharks (Galeocerdo cuvier) in coastal Hawaiian waters. Mar Biol 134:665-673

Kneebone J, Natanson LJ, Andrews AH, Howell WH (2008) Using bomb radiocarbon analyses to validate age and growth estimates for the tiger shark, Galeocerdo cuvier, in the western North Atlantic. Mar Biol 154:423-434

Kohler NE, Casey JG, Turner PA (1998) NMFS cooperative shark tagging program, 1962-93: an atlas of shark tag and recapture data. Mar Fish Rev 60:1-87

- López JA, Ryburn JA, Fedrigo O, Naylor GJP (2006) Phylogeny of sharks of the family Triakidae (Carcharhiniformes) and its implications for the evolution of carcharhiniform placental viviparity. Mol Phylogenet Evol 40: $50-60$

Lorenzen K (1996) The relationship between body weight and 
natural mortality in juvenile and adult fish: a comparison of natural ecosystems and aquaculture. J Fish Biol 49: 627-647

Manire CA, Gruber SH (1993) A preliminary estimate of natural mortality of age-0 lemon sharks, Negaprion brevirostris. NOAA Tech Rep 115:65-71

McGurk MD (1986) Natural mortality of marine pelagic fish eggs and larvae: role of spatial patchiness. Mar Ecol Prog Ser 34:227-242

Meek A (1916) The migrations of fish. Edward Arnold, London

Natanson LJ, Casey JG, Kohler NE, Colket T IV (1998) Growth of the tiger shark, Galeocerdo cuvier, in the western North Atlantic based on tag returns and length frequencies; and a note on the effects of tagging. Fish Bull (Wash DC) 97: 944-953

NMFS (National Marine Fisheries Service) (1999) Final fishery management plan for Atlantic tunas, swordfish and sharks. Highly Migratory Species Management Division,

Editorial responsibility: Matthias Seaman, Oldendorf/Luhe, Germany
Office of Sustainable Fisheries, NMFS, Silver Springs, MD NMFS (2007) NMFS annual commercial landings statistics. Available at www.st.nmfs.gov/st1/commercial/landings/ annual_landings.html. Accessed 2 July 2007

Peterson I, Wroblewski JS (1984) Mortality rates of fishes in the pelagic ecosystem. Can J Fish Aquat Sci 41:1117-1120

Pratt HL Jr (1978) Reproduction in the blue shark, Prionace glauca. Fish Bull (Wash DC) 77:445-470

Smith PC, Hale LF, Carlson JK (2006) The directed shark longline fishery: catch and bycatch, 2005. NMFS Sustainable Fisheries Division Contribution No. PCB-06, p 1-14

Smith SE, Au DW, Show C (1998) Intrinsic rebound potentials of 26 species of Pacific sharks. Mar Freshw Res 49:663-678 Springer S (1967) Social organization of shark populations. In: Gibert PW, Matheson RF, Rall DP (eds) Sharks, skates and rays. John Hopkins Press, Baltimore, MD, p 149-174

Wourms JP (1977) Reproduction and development in chondrichthyan fishes. Am Zool 17:379-410

Submitted: August 27, 2007; Accepted: April 10, 2008

Proofs received from author(s): May 14, 2008 